\title{
The dilemma of the forensic psychiatrist
}

\author{
Gwen Adshead and Jeanette Smith
}

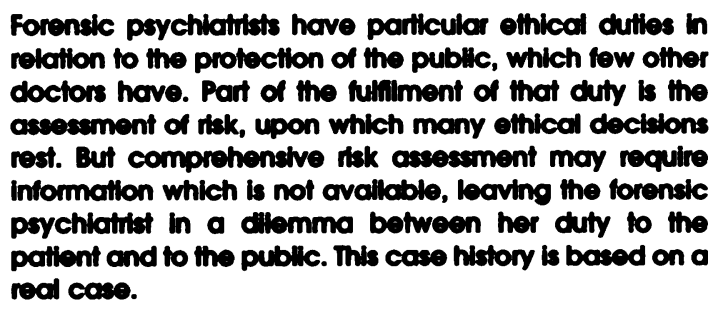

You are asked to see Mr X, a 42-year-old man convicted of burglary, who will be released in 18 months time at the end of a 12 year sentence. You have been asked to see him by the prison psychiatrist, who wants your opinion about possible transfer to hospital under section 47 of the Mental Health Act, because he is concerned that Mr X might be dangerous. Mr X's crime was to break into mortuaries, and sexually assault the dead bodies he found there (not a specific offence under English law). At the time of the trial, it was alleged that $\mathrm{Mr} \mathrm{X}$ had planned to kill people for the same purpose, although no charge was ever brought, and $\mathrm{Mr} \mathrm{X}$ has always denied it. He does not deny that he committed necrophilic acts, but claims that he was simply drunk at the time. without a partner, and feeling lonely. He is a single man, whose only enduring relationship is with his mother to whom he is said to be very close. During his sentence he has gained a first class degree in psychology. He is also a member of MENSA. His only past criminal conviction is for cruelty to animals; he mistreated his dog as a teenager, and was fined $£ 100$.

At interview, he is perfectly pleasant, and tells you that his sexual deviancy is all in the past, and he has no need for or wish to have treatment. In particular, he does not wish to go to an inpatient secure unit because he fears that his release will be delayed. No other staff within the prison express concern about him.

\section{Dilemma}

The prison could let this man go at the end of his sentence, and he may cause harm to the public as a result of his behaviour. You could detain him by transferring him to hospital under the Mental Health Act, to keep the public safe; you may have to do so indefinitely, and certainly beyond the time imposed on him by law at the time of sentencing. This may not only be legally unfair but may cause him harm.

\section{Problems}

(a) The complexity of a decision like this calls for a great deal of high quality information. The rarity of the condition in this case does not make it more complex, but adds another layer of complexity. The facts about necrophilia are not empirically good enough to justify the possible opinions that could be reached. Almost nothing is known about necrophilia: its course, its effect on dangerousness and its treatment. It is not clear whether it is a mental disorder, a disease. an illness, a sexual deviancy or simply a behaviour. This distinction is important as it would provide justification for detention under the Mental Health Act 1983. Many prisoners who have exhibited dangerous behaviours are released from prison, despite the potential risk to the public.

(b) $\mathrm{He}$ is saying very clearly that he does not think that he needs help, and does not wish to have it. To override this decision, one would have to be convinced that he was suffering from a mental disorder which would make his refusal an incompetent one, and which requires treatment. Again, the nosological status of necrophilia as a mental disorder in both these senses is unclear. (c) In relation to the possible risk to others, the evidence is not strong either way. One conviction for cruelty to animals might or might not prove a risk to humans, remembering Brittain's famous trilogy for sadism (Brittain, 1970). In any case, it can hardly be sufficient to justify detaining this man indefinitely. An allegation of intended harm to others did not result in a charge, and therefore has not been established as a proven fact in law. One might argue that it rather depends who made the allegation: if it were his mother, then one might be inclined to take this rather more seriously than if it was an acquaintance. Alone, 
it still cannot be sufficient to justify indefinite detention.

(d) It is important to remember the wrong that will be done to this man if he is detained indefinitely. He loses his liberty, but he loses it unjustly. He has already been punished for his offences; further detention will punish him for crimes that he has not committed. To detain/ punish him for crimes that he might commit lays a burden of proof on those who do the detaining to show that the risk is sufficient to justify the wrong that will be done; a burden of proof greater than that normally required by the Mental Health Act, where the purpose of detention is principally the benefit of the patient, as well as the protection of others.

(e) Further, it could be argued that this man will suffer harm from being detained. Prison is a stressful place, and so sadly are many forensic psychiatric hospitals. Indefinite detention is very stressful. Being at the whim of others is very unpleasant, no matter how benign those others appear. This sort of harm to prisoners is usually thought to be justified on the grounds of punishment (although it must be said that the length of sentence is the punishment, and not the spending of it, in legal terms); can this justification be valid for patients? In order to justify doing this man both harm and wrong the evidence of future risk ought to be stronger than it currently appears.

(f) It might be argued that this man need not be detained indefinitely. He could be admitted for assessment until date of release, then if he had no condition that made detention appropriate (ref MHA 198372 [1] b 1.), or that condition was untreatable he could be discharged. However, forensic psychiatrists know to their cost that this does not happen because the question becomes not 'Is he ill?' but 'Is he dangerous?' The man in question then has to prove a negative, which is difficult (i.e. 'I am not dangerous'). It is also absurd; everyone is dangerous in the right circumstances (cf Scott [1977)). If there is any question that he might be dangerous, then psychiatrists, wary of being criticised, will be reluctant to release him. Mr X could indeed spend a long time beyond his release date in hospital. There are no tests in forensic psychiatry that can offer this type of negative answer; 'normal' is not a frequent finding after assessment, although it may be the valid conclusion.

(g) The psychiatrist might argue that the man will benefit from being in hospital. Benefit from hospital admission would usually result from the alleviation of illness or suffering. The man himself does not think that he is ill or suffering, and current psychiatric knowledge does not offer 'treatment' for necrophilia, which might justify detention. Practically, we know it would be possible to 'fit' the behaviour into mental disorder for the purposes of the Mental Health Act, but it is hard to think that this is for the benefit of the patient, rather than for the benefit of others. It might be argued that the patient will benefit from not being able to harm others; but this could surely only be true in those cases where there was a high risk of future harm. For example, one would not wish to detain this man in order to prevent him having a car accident where another person is injured. Furthermore, if one took this argument to its logical conclusion. all sentenced prisoners nearing release could be offered a chance to 'benefit' from hospital admission.

(h) Arguably, in this case, there is no specific doctor-patient relationship between you and $\mathrm{Mr}$ $X$ which could give rise to traditional ethical duties. It could therefore be argued that the forensic psychiatrist is under no obligation to benefit Mr X, but only to do that which will benefit the public. However psychiatrists have a particular professional duty to practice justly. given the important influence they can have over the social control of deviance. Further, many might argue that $\mathrm{Mr} \mathrm{X}$ does have a claim upon your best care, as a direct result of your consultation.

\section{Conclusion}

Although apparently unusual, this case raises many common problems for forensic psychiatrists. It is often not clear precisely when people become the patients of forensic psychiatrists. In order to decide whether Mr X's legal rights should be infringed, the psychiatrist will have to establish the degree of risk. But the quality and the nature of the evidence that is avallable is often very poor; the psychiatrist can perhaps only establish a low degree of certainty as to risk, or claim an intuition based on experience. But given the wrong, and possible harm, that will be done to this man if the estimate of risk is wrong, then it seems plausible to demand a high degree of factual certainty. 'Beyond reasonable doubt' is the test for certainty in criminal law; why not when assessing risk of crime?

The public is threatened by many things, most of which are nothing to do with psychiatry, such as drunk drivers and reckless political ideologies. Not all these risks are prevented (although they may be preventable), and the public has to live with them. It seems unreasonable to take greater precautions against risks whose size is virtually unknown, than against risks whose size is known to some degree (such as car accidents).

We would therefore argue that $\mathrm{Mr} \mathrm{X}$ should be acknowledged to present a risk of unknown 
degree to the public, but that certainty of this risk is not sufficient to detain him in hospital. Further, we would argue that the psychiatric professional body needs to debate within itself about the role of forensic psychiatrists in protecting the public, and that there need to be professionally agreed guidelines about risk assessment. (Monahan, 1992, 1993). Finally, in the event of $\mathrm{Mr} \mathrm{X}$ offending in the future, we would claim that there is no causal responsibility where there is no certain or reasonably certain foreknowledge.

In a similar case, $\mathrm{Mr} \mathrm{X}$ was admitted to a Special Hospital. He remains there. He would like to leave.

\section{References}

BRTTAIN, R. (1970) The sadistic murderer. Medictne, Sctence and the Law, 10, 198-207.

MONAGHAN, J. (1992) Mental disorder and violent behaviour. American Psychologist, 47, 511-521.

- (1993) Limiting therapist exposure to Tarasoff liability. American Psychologist, 48, 242-250.

ScoTt, P. (1977) Assessing dangerousness in criminals. British Journal of Psychiatry. 131, 127-142.

Gwen Adshead, Lecturer, Department of Forensic Psychiatry, Institute of Psychiatry, De Crespigny Park, London SE5 8AF and Jeanette Smith, Senior Registrar, Fromeside Clinic, Blackberry Hill, Bristol BS16 1ED

\title{
Perception of equivalent doses of neuroleptic drugs
}

\author{
R. Mullen, A.W. Caan and S. Smith
}

\begin{abstract}
An anonymous questionnaire was sent to 67 senior and junior psychiatrists enculing about their perception of equivalent antipsychotic dosages of three commonly used neuroleptic drugs. Thitty-one questionnaires were retumed and revealed a wide variation in percelved potencies for the specilic drugs. Increased experience in psychiatry was not associated with a decreased variation. On average clinicians saw haloperidol and liupenthixol decanoate as substantially less potent, relative to chiorpromazine, than the avallable literature would suggest.
\end{abstract}

The adverse consequences of excessive or inadequate dosage of neuroleptics are well recognised. Despite gaining scant empirical attention, the problem of choosing the correct dose of an antipsychotic drug in a clinical setting is common. Appropriate dosing requires a recognition that antipsychotic drugs vary in potency.

Except for some atypical antipsychotic drugs, it is accepted from radioligand studies that effective antipsychotics displace ligands from dopamine receptors with a facility that correlates highly with their antipsychotic potency (Peroutka \& Snyder, 1980). From this robust psychopharmacological finding, the concept of equivalent doses of different neuroleptics arises.

Recent publicity about high rates of side effects and occasional deaths on high doses have brought the issue of dosage into focus. It has been postulated (Krakowski et al, 1993) that some patients receive high doses of neuroleptics because of ignorance about the efficacy of low doses. Our concern here is that clinicians may not be fully aware of what constitutes a high, or a low, dose of these drugs.

The study reported here sought to audit clinicians' knowledge of neuroleptic equivalence.

\section{The study}

We used a postal questionnaire survey. Sixtyseven psychiatrists working at junior and senior level at the Bethlem Royal \& Maudsley Special Health Authority, with responsibilities in adult psychiatry, were sent a vignette involving a patient transferred from chlorpromazine (the usual reference drug for antipsychotic equivalence) to other widely used neuroleptics. The vignette read:

A young man with chronic schizophrenia is well stabilised on a total daily dose of $500 \mathrm{mg}$ of chlorpromazine. Because of oversedation, you wish to substitute a different neuroleptic. Please indicate what dose or dose range you would consider to be of equivalent antipsychotic potency for the following drugs: 